\title{
Application of monitoring technology in deep foundation pit engineering
}

\author{
Zhineng Tong \\ Jiangxi science and technology Normal University China
}

Keywords: Deep foundation pit, Support, Monitor

\begin{abstract}
With the city's high-rise buildings have sprung up, deep foundation pit project is also more and more, more and more deep, nature of the underground soil, load conditions, the construction environment of complexity, simple based on the geological survey data and laboratory soil test parameters to determine design and construction scheme, often containing many uncertain factors. In order to ensure the safety of foundation pit construction, the foundation pit monitoring can timely detection and forecasting the danger and danger degree of development, through the construction of accurate and timely monitoring information, judge the safety state of the engineering, can guide the excavation and support protection, to take timely emergency measures, avoid or reduce the destructive consequences.
\end{abstract}

\section{The necessity of deep foundation pit monitoring}

For the stringent requirements of the large and medium-sized complex engineering or environmental projects, are often difficult to from the past experience get reference, is also difficult to theoretically to find the quantitative analysis and prediction method, which is bound to depend on the field monitoring in construction process. First of all, rely on site monitoring to understand the design strength of foundation pit, to provide design basis for the follow-up to reduce the engineering cost index. Second, timely understanding of the construction environment, underground soil, underground pipelines, underground facilities, buildings affected in the construction process and effect. Third, can be found in a timely manner and forecasting the danger of the occurrence and danger degree of development, to take timely remedial measures for safety acts as the eyes and ears. To obtain a large amount of test data in the monitoring of engineering experience and has important significance to improve the design level of foundation pit support, improve the.

\section{Characteristics and contents of deep foundation pit monitoring}

The monitoring of foundation pit has the characteristics of high efficiency, high precision, and so on. Measurement results are dynamic, the day before (and even a few hours ago) measurement results will lose the significance of the direct, so deep foundation pit construction monitoring should be carried out at any time, in the critical period of the measuring object change fast may every day for several times, the foundation pit monitoring effectiveness for a given period of time requirements corresponding method and apparatus with fast data acquisition, ability to work around the clock, even to night or in thick fog weather harsh environmental conditions. The value is usually within a few mm limit error in engineering measurement, so the measurement of foundation pit construction usually uses some special high precision instrument. Monitoring in foundation pit construction usually requires only the measured relative change value, and does not require the measurement of absolute value, as much as possible to achieve the accuracy requirements of foundation pit monitoring. Using the same instrument in the same position, by the same observer according to the same survey scheme.

Deep foundation pit safety numerous factors, monitoring content specific have the following: supporting structure and is supporting soil lateral deformation, retaining pile for underground pile lateral displacement, pile body diagonal, horizontal displacement of supporting structure at the top, the underground water level monitoring, supporting axial force, the anchor stress monitoring, underground soil earth pressure and pore water pressure, settlement of adjacent buildings, underground pipelines and roads, pit at the end of the rebound or uplift monitoring. 
Monitoring of deep foundation pit project choice according to the specific branch support, excavation depth, the level of foundation excavation and surrounding environment and other conditions to determine the and monitoring work is mainly analysis and forecasting, information collection is the foundation, the analysis and prediction is the most important.

\section{The layout and installation of deep foundation pit monitoring points}

Reasonable layout of measuring points to economic efficiency, monitoring project selection must be based on the actual situation of the project and the need to base. In determining the layout of measuring points, must know the enclosure design scheme base of the geological conditions and the foundation pit, then according to the prediction of past experience and theory to consider the layout of measuring points and the density range.

In principle is buried in the measuring points should be before the start of the project laid to complete, and should ensure that there is a certain stable, before the project started, the static initial value should be measured from the end. Settlement and displacement measuring point should be directly installed on the monitored objects, only road underground pipeline if the excavation hole like their stalls, on the sidewalk buried concrete pile simulation as a monitoring point, then simulate the pile depth should be slightly larger than the pipeline depth and surface should be located well protection cover, more than effect on pedestrian safety. If there is a pipeline equipment (such as pipeline well, valves, etc.) on the road, you can direct their stalls on the device observations.

Establishment of first order displacement monitoring datum point

Establishment of level displacement monitoring of reference point, should according to the on-site reconnaissance, consider reference point of the stability and accuracy of observation and prevent benchmark elevation changes caused by error, near the project site away from the sides of the pit three times the excavation depth distance of stable soil to drilling in weathered rocks were emplaced three basis points to check each other, three datum points and the floor reference control point displacement level monitoring network, the specific location can be determined by the site.

At the two level embedded reference point

Buried inside the secondary reference points and reference points for floor has the advantages that the operation is convenient, from a reference point lead measurement control point is settlement and displacement in the second level monitoring network and foundation pit on each side into a linear arrangement of horizontal displacement observation point, specific locations can be determined by the site.

The layout of observation points on the top of foundation pit

The observation points of the top of the foundation pit are laid, such as the foundation pit displacement monitoring, the horizontal displacement observation points are arranged at the top of the foundation pit support structure. According to the requirements of the field plane size and measurement specifications, the spacing of $20 \sim 30 \mathrm{~m}$ is generally arranged in parallel to the retaining structure of foundation pit.

Buried water point

Foundation pit in excavation of must lower the underground water level, but in the lowering of the groundwater table is may cause the underground water level in the outside of the foundation pit leaking into the pit, the groundwater flow is one of main factors that cause the collapse, so the groundwater level monitoring is an important part to ensure the safety of foundation pit; water level monitoring pipe burying should according to the data of groundwater, containing a large quantity of water areas and strong water permeability, outside the pit close to, to 20 to $30 \mathrm{~m}$ spacing parallel to the boundary of the pit and buried, burying method and the underground soil test embedment of inclined tube of the same. 


\section{Problems in foundation pit monitoring}

Deep foundation pit engineering technology although in different areas and different geological conditions achieved a lot of successful experience, but there are still some problems for further research and improve to meet the needs of the modern economic construction. There is often support construction in deep foundation pit engineering problems are mainly the following:

Soil excavation and slope support is not complete

Common branch support construction lag in earthwork construction for a long time, and had to take secondary backfill or putting up shelves to complete branch support construction in general, earthwork excavation technology content is relatively low, the procedure is simple, management organization to. The retaining soil retaining technology is high, the process is more complex, the construction organization and management are more complex earthwork excavation. So in the process of construction, large projects are composed of professional construction team to complete earthwork respectively and retaining paid work, but most are two parallel to the contract. So in the process of construction coordination management difficult, earthwork construction units to grab progress, drag period, excavation sequence is chaotic, especially in the rainy season construction, even in spite of retaining a support construction required working face, left to support construction of the operation surface is almost unable to operate, time can not supporting support, to cause the supporting construction lags behind the earthwork construction, because a support construction operating platform completed drilling, grouting, netting and injection concrete work, and had to earthwork backfill or erection of the shelf to set the operating platform to complete the construction. This is not only difficult to ensure the progress is difficult to ensure the quality of the project, or even the occurrence of safety accidents, leaving hidden quality.

Slope repair can not reach the design, specification requirements

Often there is the phenomenon of over excavation and under the general deep foundation excavation are used mechanical excavation, artificial simple slope after the beginning of retaining soil support concrete initial spray process. And in the actual excavation, due to construction management is not in place, technical disclosure not fully, the staged excavation height, dig manipulator operation level and other factors influence making machinery after the excavation of the slope surface flatness, straightness is very irregular, and the repair of the artificial impossible depth of excavation, only machine digging surface for smoothness finishing, in no strict inspection and acceptance began to spray in early, so retaining payment appeared the overbreak and underbreak phenomenon.

The hole grouting is not in place, the soil nail or anchor bolt can not reach the design requirements

Deep foundation pit supporting with soil nailing and anchor drilling straight like for $100 \sim 150 \mathrm{~mm}$ pipe into the hole, hole depth 5 ranging, drilling through the quality of the soil also each are not identical, drilling if not carefully studied soil conditions, often resulting in a residue, residue deposition and the effect of grouting, and some even difficult hole, hole collapse, not in tendons and grouting. Furthermore, grouting ingredients arbitrarily large, grouting pipe is not in place, grouting pressure is not enough caused by insufficient length of grouting, filling degree is not enough, and make the pullout force of soil nails or anchors is not up to the design requirements, affect the quality of the project, even to deal with again and again.

The thickness of sprayed concrete is not enough and the strength is not enough

The construction of foundation pit supporting sprayed concrete is commonly used in dry mixing method jet concrete equipment. Its main characteristics are simple equipment, small size, long conveying distance, the accelerator can be in into the jet before joining machine, convenient operation, continuous spraying construction. Although dry spray equipment, simple and convenient operation, but due to the different levels of hand operation, operation methods and examination and so on, concrete rebound serious, factors and quality control of raw materials is not strict, ingredients are not allowed, maintenance is not in place, often resulting in sprayed concrete thickness is not enough, the concrete strength to meet the design requirements. 
Design and site conditions exist differences

Deep foundation pit support due to the earth pressure and the traditional theory of retaining wall earth pressure vary, there is no perfect earth pressure calculation under physiological conditions, often still use the traditional theory calculation, so the error is normal, scholars have conducted many studies, combining the necessary experience in the traditional theory of soil pressure calculation based on correction can meet the practical requirement. The safety of deep foundation pit is an extremely complex problem, and it will result in excessive deformation due to the actual engineering situation. Such as designs that do not account for the differences in geological conditions, the ground load, copy set according to the same deep pit supporting protection design will have unexpected consequences. Deep foundation pit design must be based on the actual ground may be the load, including the construction of pile load, truck, temporary facilities and nearby residential buildings, etc., to compare the correct estimate of the side pressure of the supporting structure.

In order to reduce the supporting accident, to be carefully designed, carefully constructed, strengthen supervision, protection of the pit side of the house and the environment, improve the deep foundation pit support technology and management level.

\section{Conclusions}

In the construction process of deep foundation pit, in order to the safety of foundation pit engineering and the impact on the surrounding environment have comprehensive understanding, the need of foundation pit excavation to a construction conditions of the force and deformation of the numerical and trend forecasting, to ensure the safety of the foundation pit supporting structure and adjacent buildings, in unusual circumstances timely feedback and take the necessary engineering emergency measures and construction technology for adjustment or modification of the design parameters, the accumulation of monitoring work experience, provide a basis to improve the overall level of the design and construction of foundation pit engineering. Therefore, in the construction process of foundation pit support structure, the soil around the foundation pit and the adjacent buildings for a comprehensive, systematic monitoring is very important.

The construction of the deep foundation pit should be to the development of new technology, new technology, new materials, can quicken the construction progress of the foundation pit and save cost, in order to ensure the safety of foundation pit. With the development of the times, urban high-rise buildings have sprung up, deep foundation pit project is also more and more, more and more deep, in order to ensure the safety of foundation pit construction process, foundation pit monitoring can timely detection and forecasting the danger and danger degree of development, to take timely security patch remedial measures provides a sufficient basis, therefore all the deep foundation pit shall be to do a comprehensive foundation pit monitoring.

\section{References}

[1] Building foundation design code GB5007-2002; The Chinese people's Republic of China National Standard

[2] Building foundation pit engineering monitoring technical specifications GB50497-2009

[3] Precision engineering measurement specification GB/T15314-94

[4] Building deformation measurement code JGJ 8-2007 